
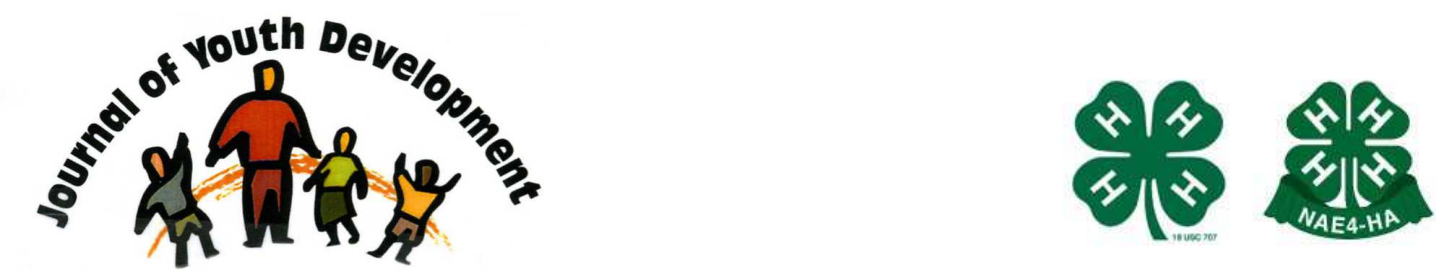

Bridging Research \& Practice

\title{
Promoting Supportive Relationships in Youth Programs: A Self-Determination Theory Perspective
}

\author{
Mat D. Duerden \\ Texas A\&M University \\ College Station, TX \\ duerden@tamu.edu
}

Ann Gillard

Texas A\&M University

College Station, TX

agillard@tamu.edu 


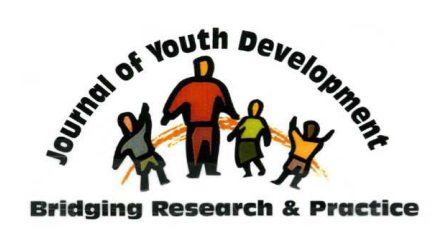

\title{
JOURNAL OF YOUTH DEVELOPMENT \\ bridging research and practice

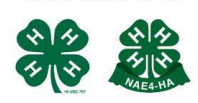

Volume 3, Number 3, Winter 2008

Article 080303FA004

\section{Promoting Supportive Relationships in Youth Programs: A Self-Determination Theory Perspective}

\author{
Mat D. Duerden and Ann Gillard \\ Texas A\&M University
}

\begin{abstract}
Although research suggests that positive contact with nonparental adults is developmentally beneficial for youth; many adolescents do not have access to such relationships. It is important that adults structure existing relationships to optimize positive youth development. Relationships with adults, who support youth's needs for autonomy, relatedness, and competence, provide youth with scaffolding as they navigate their way through adolescence. Self-Determination Theory offers a straight-forward approach to understanding the elements of contexts that best promote the development of supportive relationships. The purpose of this paper is to review the literature concerning youth-adult relationships, including their associated prevalence and developmental benefits across multiple contexts. These findings are then integrated into a framework of best practices for developing and supporting positive youth relationships with adults within youth program settings. Several theory-based recommendations are offered for youth program administrators and staff who wish to improve youth-adult relationships in their programs.
\end{abstract}

\section{Introduction}

Although theoretical approaches concerning adolescent development differ in terms of terminology, targets, and outcomes (Small, \& Memmo, 2004), consensus exists regarding the positive role of adult relationships in youth development. Research findings from the fields of prevention (Coie, et al., 1993), resilience (Benard, 1991; Werner, 1986, 1989), and positive youth development (Eccles, \& Gootman, 2002; Scales, Benson, Leffert, \& Blyth, 2000), highlight youths' need for positive adult role models. While the body of literature examining youths' 
access to and the developmental impact of supportive adult relationships is extensive in contexts, such as child-parent, student-teacher, and mentoring relationships, little research has focused on youth-adult relationships in group settings associated with youth programs (Grossman, \& Bulle, 2006).

A connection between youth-adult relationships and program outcomes is theoretically supported by Self-Determination theory (SDT), which posits that feelings of relatedness to others, along with opportunities to experience competence and autonomy, are essential prerequisites of positive development (Ryan, \& Deci, 2000b). While some attention has been given to supporting autonomy and developing competence and self-determination in youth program settings (Grossman, \& Bulle, 2006), concerted and systematic efforts to promote positive relationships with adults are lacking. Too often it is assumed that positive relationships between participants and adults automatically occur in youth programs.

Therefore, the purpose of this paper is to review the supportive adult relationship literature across a variety of contexts (e.g., school, mentoring, etc.) and then organize these findings into a SDT framework of best practices for developing positive youth-adult relationships within program settings. Before reviewing the research we will outline the major tenets of SDT. We propose that SDT provides a useful conceptual framework for integrating and applying findings concerning supportive adult relationships that could be used to improve programming in youth settings.

\section{Self-Determination Theory}

Self-Determination Theory (Deci \& Ryan, 1985) has been used to examine motivation regarding the development and functioning of personality in social contexts, and explores how people engage in behaviors with a full sense of volition, or self-determination. Social contexts may encourage or thwart the development of psychological growth and overall well-being. SDT suggests that people experience self-determination when they are internally motivated, rather than externally motivated or amotivated. The development of internally regulated behavior appears to have considerable bearing on development (Ryan, \& Deci, 2000b). Internally motivated activities prepare youth for adulthood through tasks that develop self-direction, selfexpression, and motivated involvement (Larson, \& Kleiber, 1993). Contexts that promote the basic needs of autonomy, competence and relatedness are those where internalized motivations will emerge.

Basic needs theory is one of four mini-theories that comprise SDT. This theory suggests that the needs for autonomy, relatedness and competence are fundamental, innate constructs for all people (Ryan, \& Deci, 2000b).

- Autonomy refers to the need to feel volition or decisive in one's actions. When one has choice, one can use available information to regulate themselves in the achievement of goals.

- Relatedness is the "integration of the individual into a larger social whole," and refers to the need to be connected with others (Ryan, \& Deci, 2000b).

- Competence refers to people's needs to feel self-efficacious, to believe that they are the cause of their actions, and to receive positive feedback which enhances intrinsic motivation. 
While competence is required for any type of motivation, and relatedness comes from internalizing the norms and values of the social group, autonomy is also needed for the motivation to be intrinsic (Ryan, \& Deci, 2000b).

Self-determination is optimized when the basic needs for autonomy, relatedness, and competence are met. Social contexts that support these needs are characterized by informative (not controlling) feedback from trusted others. This feedback can be competence based ("She knows what she's talking about") or relationship-based ("I like him, so I will listen to what he says"). Elements of self-determination are influenced in varying ways by the other people in the social context.

While the basic needs for autonomy, relatedness, and competence are theorized to be universal, one approach to basic needs theory is to focus on relatedness as the common thread of all three needs. Feelings of relatedness are most important for internalization and integration of the values associated with an activity because the desire for connectedness with significant others is an essential component of people's willingness to endorse such values (Ryan, \& Deci, 2000). A sense of belonging is an essential component for youth to internalize positive beliefs about themselves and others. In the following section we will review literature that addresses contexts that support these developmental needs.

\section{Literature Review}

\section{Contexts of Supportive Adult Relationships}

The topic of supportive youth-adult relationships has been studied in a variety of contexts outside of the family, such as school, one-on-one mentoring, and out-of-school time youth programs including summer camp and sports. The literature regarding supportive relationships will be reviewed through an SDT perspective for the following contexts:

(a) educational settings;

(b) one-on-one mentoring; and

(c) youth programs.

Research findings were included in the following sections if they were: 1) empirically-based; 2) SDT-based; and/or 3) measured SDT related constructs.

\section{Educational Settings}

Recent research employing SDT in educational settings has examined relationships between teachers and students. Youth spend about one-third of time during weekdays at school, mostly in the presence of teachers. Teachers can serve as positive role models as they form relationships with students. Following the tenets of SDT, teachers are integral in constructing a classroom context that supports students' autonomy, relatedness, and competence.

Researchers from diverse theoretical perspectives have documented that positive relationships between teachers and students are usually characterized by warmth and acceptance (e.g. Birch, \& Ladd, 1998; Hughes, Cavell, \& Willson, 2001) and by autonomy granting (e.g. Schweinle, Meyer, \& Turner, 2006; Zimmer-Gembeck, \& Locke, 2007). These relationships are further linked to positive developmental outcomes (e.g. Birch, \& Ladd, 1997; Gest, Welsh, \& Domitrovich, 2005). 
The classroom can be an ideal setting for studies using SDT, for it inherently affords varying degrees of opportunities for autonomy, relatedness, and competence. The traditional classroom climate, characterized by high levels of teacher control, has been criticized as providing students with little to no choice about what they learn, and how they learn it (e.g. David, Mihaly, Barbara, \& Elisa Steele, 2003; Greene, Miller, Crowson, Duke, \& Akey, 2004). Conversely, more modern educational practices have suggested that youth learn more when teachers give them choices (e.g., Schweinle, et al., 2006; Stefanou, Perencevich, DiCintio, \& Turner, 2004). For example, ninth- and tenth-grade students who felt that school teachers, parents, and school administrators acted in autonomy-supportive ways had higher levels of selfdetermined motivation to stay in school; their perceptions of these social agents' meeting their needs for competence, autonomy, or both influenced their motivation, (Vallerand, Fortier, \& Guay, 1997).

High school physical education classes have also been studied using a SDT framework. In one study, Standage, Duda, and Ntoumanis (2003) found that the manner in which students perceive situational cues from their PE teacher related to their intentions to engage in future physical activities. Students felt more autonomous, competent, and related when they perceived an autonomy-supportive environment low in controlling features, and to a lesser extent, perceived PE class as offering a mastery (e.g., cooperative, volitional) climate.

In a related study, Ntoumanis (2005) found that PE teachers' support of their 15-year-old students' needs for competence, relatedness, and autonomy positively predicted selfdetermined motivation. This was further linked to positive affective, cognitive, and behavioral outcomes, and positive intentions to engage in optional PE activities the next year. Students who felt competent in freely-chosen PE were more likely than those for whom PE was required to find it interesting and want to continue participation. Students also felt related to others in the friendships made through their PE participation. These studies suggest that students' experiences and participation levels can be influenced by opportunities for self-determined motivation.

Soenens and Vansteenkiste (2005) examined the effects of the provision of autonomy on educational outcomes. They found that teachers' support of autonomy was significantly linked to adolescent students' grade point average, levels of vocational exploration and commitment, and self-determination in school- and job-seeking behaviors. Self-determined motivation to engage in academic activities was associated with higher perceived academic competence and higher grades. As mentioned earlier, when the need for autonomy is met, self-determination to engage in prosocial behaviors often emerges.

\section{One-on-One Mentoring}

Research findings show that youth in quality mentoring relationships exhibit higher levels of school attendance and academic performance, better attitudes towards school, lower levels of substance abuse and some deviant behaviors, and improved family relationships than those without mentors (DuBois, Holloway, Valentine, \& Cooper, 2002; Grossman, \& Tierney, 1998; Jekielek, Moore, Hair, \& Scarupa, 2002). As noted, these outcomes only occur in certain types of mentoring relationships. It appears that youth realize the most benefits from mentoring when they can establish a supportive, long term relationship with a mentor who addresses their need to experience competence and autonomy. 
Certain characteristics are associated with mentoring relationships that foster feelings of relatedness. For example, the frequency of contact between mentor and mentee and the duration of their relationship appear very important. Findings from a large study of Big Brother Big Sister participants, suggest that relationships that last at least 12 months produce the greatest positive benefits, whereas relationships that last less than three months negatively impact self-worth and academic efficacy (Grossman, \& Rhodes, 2002). Similar findings show that more contact between mentors and mentees also lead to many of the same benefits mentioned earlier (DuBois, et al., 2002; Jekielek, et al., 2002). The amount of training adults receive before and during mentoring also predicts overall youth-adult relationship quality (DuBois, et al., 2002; Jekielek, et al., 2002; Karcher, Nakkula, \& Harris, 2005).

Although numerous studies examine the outcomes of mentoring programs, fewer studies consider the quality of mentoring relationships (DuBois, et al., 2002; Karcher, et al., 2005). From existing research, it appears that, as would be expected, mentor and mentee characteristics jointly influence relationships quality. In a study of older adolescent mentors, researchers found that mentors' perception of the mentor-mentee relationship was predicted by mentors' self-efficacy and mentees' propensity to seek support (Karcher, et al., 2005). Additionally, individuals who indicated extrinsic motivations (e.g., building their resume) for mentoring also reported more negative perceptions of their mentor-mentee relationships.

These findings speak to the need for adequate mentor training in order to increase levels of self-efficacy, as well as to teach mentors methods of encouraging mentees to seek their help and support (Karcher, et al., 2005). It is interesting to note that these factors are stronger predictors of relationship quality than mentee's risk status (Karcher, et al., 2005). Findings also show that shared interests between mentor and mentee is the strongest predictor of quality relationships, even more so than gender or ethnic matching (Herrera, Sipe, McClanahan, \& Arbreton, 2000).

While providing training and making good mentor-mentee matches appear to be important components of quality relationships, mentee characteristics also deserve consideration. Findings suggest that the types of youth served influences program impact and effectiveness. For instance, individuals who come from risky environments appear to experience greater benefits from mentoring than youth from less risky backgrounds (DuBois, et al., 2002). These findings do not hold true for youth with individual-level risk factors, although it may mean that mentors need additional training in order to effectively work with more behaviorally-challenged youth (DuBois, et al., 2002). These results align with Karcher, et al.'s (2005) findings discussed earlier which show that mentors' self-efficacy is a better predictor of relationship quality than mentee risk status. In other words, if mentors receive training that increases confidence in their ability to mentor, they can successfully work with more difficult youth.

Mentees perceive their mentoring relationship to be most positive when they have opportunities to engage in both social and academic activities with their mentors. This is especially the case when mentors allow them to play a role in making decisions regarding activities, thus meeting youths' need to experience autonomy and competence (Herrera, et al., 2000). Findings from a study of youths' perceptions of mentoring relationships show that youth who perceive their mentor as offering moderate levels of structure and activity participation as well as conditional support experience more positive outcomes than youth whose mentors provide either low 
structure or unconditional support (Langhout, Rhodes, \& Osborne, 2004). Mentors were most effective when they provided support contingent upon high expectations, while still allowing for active participation and independence. These findings align with outcomes associated with different parenting styles (Baumrind, 1991; Langhout, et al., 2004).

Mentoring programs, when structured effectively, have the ability to provide youth participants with a wide range of positive benefits. It appears that those relationships that best address youths' need to experience relatedness, competence and autonomy provide the greatest benefits. Certain considerations need to be taken at both the program and individual level in order to promote the development of positive mentoring relationships. Additionally, and perhaps most importantly, the efficacy of mentoring for youth from risk-laden environments lends support for the use of these programs as prevention interventions (DuBois et al., 2002).

\section{Youth Programs}

The development of positive relationships between participants and staff is often a natural byproduct of many youth programs, but evidence regarding the importance of these relationships should motivate program administrators and youth workers to intentionally design programs to promote the development of supportive adult relationships. Research in this area is lacking (Grossman, \& Bulle, 2006) as SDT has only been examined in a limited number of studies exploring these contexts. Findings regarding youth-adult relationships in similar contexts can also provide guidance for youth program staff until more specific research findings become available. Given this orientation, we will explore the research-to-date in the area of youth programs and then follow it with work completed in similar settings.

While the empirical examples in youth programs are limited, these studies do provide insight into the importance of youth-adult relationships within these contexts. For example, at a 4-H program for urban youth ages 5-19, survey results show that participants' perceptions of positive relationships with adults in the program were positively related to program attendance as well as supportive adult behaviors (Paisley, \& Ferrari, 2005). Anderson-Butcher, Cash, Saltzburg, Midle, \& Pace, (2004) examined how relationships between youth organization staff and participants in a Boys \& Girls Club program impacted academic outcomes. Relatedness was found to positively affect youth's prosocial factors at school, such as enjoyment, trying one's best, and helping others. These relationships also protected against antisocial factors such as getting sent out of class, being suspended, and other disciplinary actions. Findings from a study of an after school program aimed at increasing positive motivation in science classes showed that participants in the program exhibited higher levels of engagement in school and science class, autonomous motivation, and desire for learning for its own sake (Grolnick, Farkas, Sohmer, Michaels, \& Valsiner, 2007).

\section{Camp Settings:}

Self-determination has also been investigated in residential summer camp settings for adolescents with diabetes (Hill, \& Sibthorp, 2006; Ramsing, \& Sibthorp, 2006). Perceived autonomy support positively predicted campers' feeling competent at managing their diabetes (Hill, \& Sibthorp, 2006). Ramsing and Sibthorp (2006) found that noncompetitive activities and camper-centered approaches to instruction predicted increased perceptions of autonomy support by girls and boys at diabetes camp. However, competitive activities and leader-centered approaches to instruction led to decreased perceptions of autonomy support for girls. Art activities led to more perceptions of autonomy support than sports, games, and athletics did, 
and older campers perceived more autonomy than younger campers. These studies show that the levels of competition and autonomy, as well as interpersonal processes in the youth program climate created by adults, have effects on youth's perceptions of the provision of autonomy, relatedness, competence, and self-determination.

\section{Youth Leadership:}

Outcomes related to levels of youth leadership within programs have also been explored. Jones and Perkins (2006) found differences between demographic groups on perceptions of youth involvement in a collaborative after-school program for 13-18 year olds. Females and rural participants had more positive perceptions of youth involvement in the program when compared to males and urban participants. Additionally, youth participants and adults in youthled collaborations were significantly more positive toward youth involvement than those participants and adults in adult-led collaborations. In a similar study on leadership in youth programs, Larson, Walker, and Pearce (2005) examined qualitative differences between four high school programs that employed different approaches to youth involvement in program leadership. Youth-led approaches contributed to feelings of youth ownership of and investment in the program, which made them feel more competent and motivated within the program as well as other areas of their lives. For example, participants developed greater acceptance of diversity, and a greater commitment to their education. However, one of the risks of this approach was the possibility of getting off track from the goals. Adult-led approaches resulted in feelings of competence in technical skills, as well as in self-confidence, interpersonal skills, and a sense of responsibility. A risk of this approach was that adults could undermine youth's ownership. This study's suggestions coincide with other work in this area (Larson, 2006) that relationships between youth and adults should be intentionally balanced so as to keep work in the program on track while keeping youth actively invested.

\section{Sports:}

Sports represent another context where young people have opportunities to interact with adults, namely their coaches. Research has shown that coaches can developmentally impact the players on their teams. For example, findings from a study of the influence of coaches on competitive high school swimmers' motivations suggest that controlling coaches negatively impacted swimmers' motivations to participate in competitive swimming, whereas swimmers with non-controlling and autonomy supportive coaches exhibited higher levels of intrinsic motivation and persistence (Pelletier, Fortier, Vallerand, \& Briere, 2001).

It also appears that coaches' ability to positively influence youth can be greatly enhanced through short-term training interventions. Findings from a study of social support training for coaches showed that players whose coaches participated in the two and a half hour training had more fun during the season and gave their coaches higher ratings than players whose coaches did not receive the same training (Smoll, Smith, Barnett, \& Everett, 1993). The same study also found that boys with low self-esteem who played for the trained coaches experienced significant self-esteem growth over the course the season in comparison to the control group. These findings are particularly exciting in terms of promoting the development of supportive adult relationships because they show that short-term training interventions can improve preexisting youth-adult relationships and positively impact important internal capacities such as self-esteem. 
Youth program settings such as summer camps, after-school programs, and sports can be contexts where opportunities for autonomy, relatedness, and competence are provided by supportive adults. The structure of out-of-school time (OST) programs lends itself to the development of these important developmental processes, for in OST exists a greater freedom for youth to engage in relationships with non-parental and non-teacher adults in a nurturing, experiential climate. While youth may only spend a few hours per week with adults in OST settings, these interactions can be more intensive than student-teacher relationships due to lower youth-adult ratios and opportunities for engagement in a diverse array of activities.

\section{Practical Implications}

Although the majority of findings reviewed in this paper deal with contexts other than OST youth programs, it is our belief that this combined body of knowledge can inform youth organization policy and practice. Additionally, the tenets of SDT provide guidance for organizing these findings into an applicable framework for promoting relationships in youth programs. Organized youth programs, when structured appropriately, can provide a fertile context for youth to form relationships with positive adults in group settings outside of home or school. Youth programs are often more flexible than school settings that are constrained by curricula, policy, and the pressures of standardized testing. Youth programs can supplement the influence of the home and school by introducing youth to new people, ideas, and diversity of experiences that can help build social skills, and positively influence development.

There exist several levels of influence within youth programs ranging from administrative policy to direct interactions between youth and adults. The following sections will outline an SDT framework of proposed best practices at the administrative and direct service levels for developing youth programs that promote supportive relationships between youth and adults.

\section{Administrative Best Practices}

Youth program administrators affect youth-adult relationships through program design and implementation. While the climate of a program is largely based on interactions between program staff and youth, administrative policy influences these relationships through hiring, programming, and policy. For example, school policy affects teacher-student relationships through adult-child ratios; length of contact between students and teachers; transitions and stability of contact; and school organization, climate, and culture (Pianta, 1999).

Administrators need to develop policy and programming to create an environment that will enable participants to meet their need for relatedness through the development of positive relationships with program adults. As discussed earlier, appropriate levels of duration and frequency are necessary to optimize benefits inherent to youth-adult relationships.

Administrators should make it clear during hiring and training that staff are expected to work for at least a year and develop positive personnel policies and working environments to support staff.

Findings also show that youth-adult relationships are enriched through participation in social, structured, and unstructured activities (Grossman, \& Bulle, 2006; Herrera et al., 2000). It is also important that youth play a role in the decision making and programming process; such a policy meets youths' need for autonomy and appears to strengthen their relationships with adults (Herrera, et al., 2000). Administrators need to evaluate the breadth of their current program 
offerings and add additional components if the variety is lacking, as well as allow flexibility for the expression of youth voice (Ellis, \& Caldwell, 2005) and decision making.

The training of staff is another area where administrators can have an impact on their organization's ability to meet youths' need for relatedness, autonomy, and competence. Through the establishment of a quality and targeted training program, administrators can develop staff equipped to develop relationships with youth in a way that will promote autonomy and competence. Although the research is limited regarding the training of youth workers, short-term training programs for youth sports coaches appear efficacious (Smoll, et al., 1993).

In order to promote the development of long-term, stable relationships, staff training programs should occur before and during programs (DuBois, et al., 2002; Jekielek, et al., 2002; Karcher, et al., 2005). Training should focus on teaching staff how to find ways to connect with youth to build positive youth-adult relationships. Two key predictors of such positive relationships are identifying similar interests for youth and staff, and creating environments in which youth feel comfortable seeking support from staff (Herrera, et al., 2000; Karcher, et al., 2005). Training should also focus more on building general youth worker/mentoring competencies rather than preparing staff to deal with specific at-risk behaviors since general levels of mentoring selfefficacy have been shown to be better predictors of positive relationships than youths' at-risk status (Karcher, 2005). Such a training program could consist of pre-mentoring workshops supplemented by regular, scheduled contact with program supervisors once mentoring begins. Continued administrative oversight of mentoring relationship helps ensure program implementation (DuBois, et al., 2002; Jekielek, et al., 2002). Research shows such supervision also leads to increased contact between mentors and mentees (Herrera, et al., 2000).

Staff should understand the balance they need to establish in terms of structure, support, and activity participation. Research shows that youth gain the greatest benefits when adults provide moderate levels of structured and unstructured activities. Staff should also offer support based upon agreed-upon expectations for appropriate behavior (Langhout, et al., 2004). Program staff also need to understand the perspectives and experiences of youth, both as individuals and as members of unique contexts (i.e. family, community, ethnic, etc.; Larson, et al., 2005). Policy and staff training can create an environment and culture where supportive adult relationships thrive. Although further research is needed to validate these proposed best practices, findings from other contexts support their effectiveness. It is also worth noting that relationships between administrators and program youth leaders may affect relationships between youth leaders and youth. Accordingly, one way to prepare youth leaders to foster feelings of relatedness, autonomy, and competence among the youth is to provide these same conditions for youth workers. Administrators' efforts to enact policy, programming, and training procedures lay the foundation for the development of supportive relationships between youth and program staff. The following section presents ideas regarding how staff can most effectively interact with youth in order to promote competence and autonomy.

\section{Interpersonal Best Practices}

Direct interactions between youth and adults are the touchstone of youth's feelings of connectedness to youth programs (Pearce, \& Larson, 2006). Pianta (1999) suggests that such relationships can be thought of as a system comprised of: representations, feedback mechanisms, tolerances, timing of interactions, and contingency of interactions. While there are several different approaches to establishing supportive relationships with youth, many 
similarities exist across approaches that suggest that the provision of opportunities for autonomy, competence, and relatedness lead to effective youth-adult relationships.

Autonomy-supportive teaching styles are those in which teachers provide a sense of volition by being sensitive to students' needs, and also affording choices to students (Soenens, \& Vansteenkiste, 2005). Adults can support autonomy by providing information about options and actions; acknowledging feelings; incorporating student perspectives into activities; providing optimally challenging tasks; providing structure and guidance that demonstrate the reasons for certain behaviors; and minimizing a performance-based climate (Eisenman, 2007). Autonomy support can also occur in environments that include opportunities for youth to evaluate their own performances, have choices, learn how to find information, and understand rationales for behavior change that are relevant to them (Hill, \& Sibthorp, 2006).

Autonomy-supportive contexts are those that provide youth with a sense of personal choice and involvement, and are provided by adults who actively engage youth in being the agents of their experiences. In coaching contexts, group structures that are autonomy-supportive and masteryfocused can promote self-determination to engage in physical activity (Standage, Duda, \& Ntoumanis, 2003). When coaches provide adolescent athletes with a sense of choice, meaningful rationale for behaviors, and freedom from external pressure, athletes are more likely to internalize the positive values (e.g., goal-directed behavior, persistence, etc.) inherent to competitive sports (Pelletier, et al., 2001). Interactions with coaches lead to feelings of autonomy when the coach takes the athlete's perspective, provides choice, reflects the other's feelings, and encourages initiative.

A competence-supporting environment is one that provides youth with positive feedback on their skill development and creates feelings of self-efficacy. Such experiences can lead to selfdetermined motivation. Eisenman (2007) suggests that there are specific activities that adults can do to teach students to be self-determined by modeling problem solving, setting performance goals, monitoring completion of tasks, and evaluating products. Contexts that support youth's needs for competence are those that also have a high quality of relatedness with the adult who appropriately organizes the activity to maximize skill-building, and provides effective positive feedback.

While relatedness is a need that can be met within the provision of autonomy and competence, there are some steps that adults can take to meet the need of youth to feel related and connected to others. For example, in a review of studies on relationships between teachers and early adolescents with high-incidence disabilities, Murray (2002) suggested the following for improving relationships:

- Recognize that youth need to feel supported by adults;

- Provide students with opportunities to learn positive relationship skills with adults;

- Learn more about students' backgrounds, interests, and communities;

- Develop increased awareness of classroom interactions; and

- Model and expect appropriate behavior.

Effective interpersonal behaviors can include talking to a child in a positive tone, giving a child clear directions, listening to a child, and using a child's name when talking to him or her (Paisley, \& Ferrari, 2005). Such approaches to building relationships should be tuned to be age- 
appropriate; for example, teens may find teachers' frequent use of their names to be patronizing, whereas seven year old children may not.

Individual youth characteristics should be considered as well. For example, in groups with students who have low-acceptance by peers or are aggressive, social skills training interventions can be used to focus on the affective quality of teacher-student interactions by increasing teacher support of students through proactive positive comments and gestures (Hughes, et al., 2001). Also, Guzick, Dorman, Groff, Altermatt, and Forsyth (2004) suggest that for youth who are low on social liking and social empathy, an appropriate approach by adults would be to foster good relationships with students by focusing on praise and refraining from ridicule; in other words, being "cultivators rather than weeders," (p. 367). Youth's need for relatedness can be met in contexts that are characterized by caring, interested, and sensitive adult role models.

The interpersonal relationships between youth and adults can serve as opportunities to meet needs for autonomy, relatedness, and competence. The meeting of such needs is integral to youth development, and can carry over into other parts of youth's lives. While actual interaction time with adults in youth programs may be small when compared to interactions with adult family members and teachers at school, the experience of a diverse support system of caring adults strengthens youth by providing additional resources that promote their development.

\section{Conclusion}

The merit of youth programs lies in their ability to foster relationships between youth and supportive, caring adults. A SDT approach to relationship development organizes empiricallybased information and practices that can inform practitioners as they create supportive relationships that meet youth's needs. The implications from this article represent not so much a new method of youth development, but a synthesized, youth-centered application of preexisting research and practice. While further research is needed to test this claim, it is believed that the application of this framework will result in increased participation in youth programs and psychological well-being.

Note: The authors wish to thank Dr. Jan Hughes for her valuable support in the development of this article. This research was supported by the Elda K. Bradberry Recreation and Youth Development Chair.

\section{References}

Anderson-Butcher, D., Cash, S.J., Saltzburg, S., Midle, T., \& Pace, D. (2004). Institutions of youth development: The significance of supportive staff-youth relationships. Journal of human behavior in the social environment, $9(1-2), 83-99$.

Baumrind, D. (1991). Effective parenting during the early adolescent transition. In P. A. Cowan \& M. Hetherington (Eds.), Family Transitions (pp. 111-163). Hillsdale, NJ: Lawrence Erlbaum.

Benard, B. (1991). Fostering resiliency in kids: Protective factors in the family, school, and community. Portland, OR: Western Regional Center for Drug-Free Schools and Communities. 
Birch, S.H., \& Ladd, G.W. (1997). The teacher-child relationship and children's early school adjustment. Journal of School Psychology, 35(1), 61-79.

Birch, S.H., \& Ladd, G.W. (1998). Children's Interpersonal Behaviors and the Teacher-Child Relationship. Developmental Psychology, 34(5), 934.

Coie, J.D., Watt, N.F., West, S.G., Hawkins, J.D., Asarnow, J.R., Markman, H.J., et al. (1993). The science of prevention: A conceptual framework and some directions for a national research program. American Psychologist, 48(10), 1013-1022.

Deci, E.L., \& Ryan, R.M. (1985). Intrinsic motivation and self-determination in human development. New York, NY: Plenum.

DuBois, D.L., Holloway, B.E., Valentine, J.C., \& Cooper, H. (2002). Effectiveness of Mentoring Programs for Youth: A meta-analytic review. American Journal of Community Psychology, 30(2), 157-197.

Eccles, J.S., \& Gootman, J.A. (Eds.). (2002). Community programs to promote youth development. Washington, DC: National Academy Press.

Eisenman, L.T. (2007). Self-determination interventions: Building a foundation for school completion. Remedial and Special Education, 28(1), 2-8.

Ellis, J.M., \& Caldwell, L.L. (2005). Increasing youth voice. In P. A. Witt \& L. L. Caldwell (Eds.), Recreation and Youth Development (pp. 281-299). State College, PA: Venture Publishing.

Gest, S.D., Welsh, J.A., \& Domitrovich, C.E. (2005). Behavioral predictors of changes in social relatedness and liking school in elementary school. Journal of School Psychology, 43(4), 281301.

Grolnick, W.S., Farkas, M.S., Sohmer, R., Michaels, S., \& Valsiner, J. (2007). Facilitating motivation in young adolescents: Effects of an after-school program. Journal of Applied Developmental Psychology, 28, 332-344.

Grossman, J.B., \& Bulle, M.J. (2006). Review of what youth programs do to increase connectedness of youth with adults. Journal of Adolescent Health, 39, 788-799.

Grossman, J.B., \& Rhodes, J.E. (2002). The test of time: Predictors and effects of duration in youth mentoring relationships. American Journal of Community Psychology, 30(2), 199-219.

Grossman, J.B., \& Tierney, J.P. (1998). Does Mentoring Work?: An impact study of the Big Brothers Big Sisters program. Evaluation Review, 22(3), 403.

Guzick, D.T., Dorman, W.J., Groff, T.S., Altermatt, E.R., \& Forsyth, G.A. (2004). Fostering social interest in schools for long-term and short-term outcomes. Journal of Individual Psychology, 60(4), 361-378. 
Herrera, C., Sipe, C.L., McClanahan, W.S., \& Arbreton, A.J.A. (2000). Relationship development in community-based and school-based programs. Philadelphia, PA: Public/Private Ventures.

Hill, E., \& Sibthorp, J. (2006). Autonomy support at diabetes camp: a self determination theory approach to therapeutic recreation. Therapeutic Recreation Journal, 40(2), 107-125.

Hughes, J.N., Cavell, T.A., \& Willson, V. (2001). Further support for the developmental significance of the quality of the teacher-student relationship. Journal of School Psychology, 39(4), 289-301.

Jekielek, M.A., Moore, K.A., Hair, E.C., \& Scarupa, H.J. (2002). Mentoring: A promising strategy for youth development. Washington, D.C.: Child Trends.

Jones, K.R., \& Perkins, D.F. (2006). Youth and adult perceptions of their relationships within community-based youth programs. Youth \& Society, 38(1), 90.

Karcher, M.J. (2005). The effects of developmental mentoring and high school mentors' attendance on their younger mentees' self-esteem, social skills, and connectedness. Psychology in the Schools, 42(1), 65.

Karcher, M.J., Nakkula, M.J., \& Harris, J. (2005). Developmental mentoring match characteristics: Correspondence between mentors' and mentees' assessments of relationship quality. The Journal of Primary Prevention, 26(2), 93-110.

Langhout, R.D., Rhodes, J.E., \& Osborne, L.N. (2004). An Exploratory Study of Youth Mentoring in an Urban Context: Adolescents' Perceptions of Relationship Styles. Journal of Youth \& Adolescence, 33(4), 293.

Larson, R. (2006). Positive youth development, willful adolescents, and mentoring. Journal of Community Psychology, 34(6), 677-689.

Larson, R.W., \& Kleiber, D. (1993). Daily experience of adolescents. In P. Tolan \& B. Cohler (Eds.), Handbook of clinical research and practice with adolescents (pp. 125-145). New York, NY: Wiley.

Larson, R.W., Walker, K., \& Pearce, N. (2005). A comparison of youth-driven and adult-driven youth programs: Balancing inputs from youth and adults. Journal of Community Psychology, 33(1), 57-74.

Murray, C. (2002). Supportive teacher-student relationships: Promoting the social and emotional health of early adolescents with high incidence disabilities. Childhood Education, 78(5), 285291.

Ntoumanis, N. (2005). A prospective study of participation in optional school physical education using a self-determination theory framework. Journal of Educational Psychology, 97, 444-453.

Paisley, J.E., \& Ferrari, T.M. (2005). Extent of positive youth-adult relationships in a 4-H after school program. Journal of Extension. 
Pearce, N.J., \& Larson, R. (2006). How teens become engaged in youth development programs: The process of motivational change in a civic activism organization. Applied Developmental Science, 10(3), 121-131.

Pelletier, L.G., Fortier, M.S., Vallerand, R.J., \& Briere, N.M. (2001). Associations among perceived autonomy support, forms of self-regulation, and persistence: A prospective study. Motivation \& Emotion, 25(4), 279-306.

Pianta, R.C. (1999). Enhancing relationships between children and teachers. Washington, DC: American Psychological Association.

Ramsing, R., \& Sibthorp, J. (2006). Predictors of autonomy support at diabetes summer camp: A self-determination theory approach. Paper presented at the Meeting of the Coalition for Education in the Outdoors: Eight Biennial Research Symposium, Matinsville, IN.

Ryan, R.M., \& Deci, E.L. (2000a). The darker and brighter sides of human existence: Basic psychological needs as a unifying concept. Psychological Inquiry, 11(4), 319-338.

Ryan, R.M., \& Deci, E.L. (2000b). Self-determination theory and the facilitation of intrinsic motivation, social development, and well-being. American Psychologist, 55(1), 68.

Scales, P.C., Benson, P.L., Leffert, N., \& Blyth, D.A. (2000). Contribution of developmental assets to the prediction of thriving among adolescents. Applied Developmental Science, $4(1)$, 27-46.

Schweinle, A., Meyer, D.K., \& Turner, J.C. (2006). Striking the Right Balance: Students' Motivation and Affect in Elementary Mathematics. Journal of Educational Research, 99(5), 271293.

Small, S., \& Memmo, M. (2004). Contemporary models of youth development and problem prevention: Toward an integration of terms, concepts, and models. Family Relations, 53(1), 311.

Smoll, F.L., Smith, R.E., Barnett, N.P., \& Everett, J.J. (1993). Enhancement of children's selfesteem through social support training for youth sport coaches. Journal of Applied Psychology, 78(4), 602-610.

Soenens, B., \& Vansteenkiste, M. (2005). Antecedents and outcomes of self-determination in 3 life domains: The role of parents' and teachers' autonomy support. Journal of Youth and Adolescence, 34(6), 589-604.

Standage, M., Duda, J.L., \& Ntoumanis, N. (2003). Predicting motivational regulations in physical education: The interplay between dispositional goal orientations, motivational climate and perceived competence. Journal of Sports Sciences, 21(8), 631-647. 
Vallerand, R.J., Fortier, M.S., \& Guay, F. (1997). Self-determination and persistence in a real-life setting: Toward a motivational model of high school dropout. Journal of Personality and Social Psychology, 72(5), 1161-1176.

Werner, E.E. (1986). Resilient offspring of alcoholics: A longitudinal study from birth to age 18. Journal of Studies on Alcohol, 47, 34-30.

Werner, E.E. (1989). High-risk children in young adulthood: A longitudinal study from birth to 32 years. American Journal of Orthopsychiatry, 59(1), 72-81.

Zimmer-Gembeck, M.J., \& Locke, E.M. (2007). The socialization of adolescent coping behaviours: Relationships with families and teachers. Journal of Adolescence, 30(1), 1-16.

(C) Copyright of Journal of Youth Development Bridging Research and Practice. Content may not be copied or emailed to multiple sites or posted to a listserv without copyright holder's express written permission. Contact Editor at: patricia.dawson@oregonstate.edu for details. However, users may print, download or email articles for individual use.

ISSN 2325-4009 (Print); ISSN 2325-4017 (Online) 